\title{
Exposure of keratinocytes to non-thermal dielectric barrier discharge plasma increases the level of 8-oxoguanine via inhibition of its repair enzyme
}

\author{
KI CHEON KIM ${ }^{1}$, MADDUMA HEWAGE SUSARA RUWAN KUMARA ${ }^{1}$, KYOUNG AH KANG ${ }^{1}$, \\ MEI JING PIAO ${ }^{1}$, MIN CHANG OH ${ }^{1}$, YEA SEONG RYU ${ }^{1}$, JIN OH JO ${ }^{2}$, YOUNG SUN MOK ${ }^{2}$, \\ JENNIFER H. SHIN ${ }^{3}$, YEUNSOO PARK ${ }^{4}$, SEONG BONG KIM ${ }^{4}$, SUK JAE YOO ${ }^{4}$ and JIN WON HYUN ${ }^{1}$ \\ Departments of ${ }^{1}$ Biochemistry, School of Medicine and Institute for Nuclear Science and Technology and \\ ${ }^{2}$ Chemical and Biological Engineering, Jeju National University, Jeju 63243; ${ }^{3}$ Department of \\ Mechanical Engineering, Korea Advanced Institute of Science and Technology, Daejeon 34141; \\ ${ }^{4}$ Plasma Technology Research Center, National Fusion Research Institute, Gunsan 54004, Republic of Korea
}

Received January 22, 2016; Accepted January 27, 2017

DOI: $10.3892 / \mathrm{mmr} .2017 .7454$

\begin{abstract}
Oxidative stress enhances cellular DNA oxidation and may cause mutations in DNA bases, including 8-oxoguanine (8-oxoG). Our recent study reported that exposure of cells to non-thermal dielectric barrier discharge (DBD) plasma generates reactive oxygen species and damages DNA. The present study investigated the effect of non-thermal DBD plasma exposure on the formation of 8-oxoG in $\mathrm{HaCaT}$ human keratinocytes. Cells exposed to DBD plasma exhibited increased level of 8-oxoG. In addition, mRNA and protein expression levels of 8-oxoguanine glycosylase 1 (OGG1), an 8-oxoG repair enzyme, were reduced in plasma-exposed cells. Furthermore, the expression level of nuclear factor erythroid 2-related factor 2 ( Nrf2), a transcription factor that regulates OGG1 gene expression, was reduced following exposure to DBD plasma. Pretreatment of cells with an antioxidant, N-acetyl cysteine (NAC), prior to plasma exposure suppressed the formation of 8-oxoG and restored the expression levels of OGG1 and Nrf2. In addition, phosphorylation of protein kinase B (Akt), which regulates the activation of Nrf2, was reduced following plasma exposure. However, phosphorylation was restored by pretreatment with NAC. These findings suggested that non-thermal DBD plasma exposure generates 8-oxoG via inhibition of the Akt-Nrf2-OGG1 signaling pathway in HaCaT cells.
\end{abstract}

Correspondence to: Professor Jin Won Hyun, Department of Biochemistry, School of Medicine and Institute for Nuclear Science and Technology, Jeju National University, 102 Jejudaehak-ro, Jeju 63243, Republic of Korea

E-mail: jinwonh@jejunu.ac.kr

Key words: non-thermal dielectric barrier discharge plasma, reactive oxygen species, 8 -oxoguanine, 8 -oxoguanine glycosylase 1 , nuclear factor erythroid 2-related factor 2

\section{Introduction}

8-Oxoguanine (8-oxoG) is an oxidized form of a DNA base and is considered to be a cellular marker for oxidative stress-induced DNA damage (1). The 8-oxoG may pair with adenine and cytosine at an almost equal ratio, resulting in guanine to adenine and cytosine to thymine base substitutions during replication (2). Removal of 8-oxoG is a multi-step process that relies on three proteins encoded by the mut homolog 1 (MTH1), mutY DNA glycosylase (MUTYH) and 8-oxoG DNA glycosylase $(O G G 1)$ genes (3). The MTH1 protein hydrolyzes 8-oxoG-triphospate to produce 8-oxoG-monophosphate. This strategy avoids incorporation of oxidized foreign nucleotides into the genome. Human OGG1 may efficiently catalyze the splitting of an $\mathrm{N}$-glycosidic bond between a deoxyribose sugar and the damaged 8-oxoG base (4-7). Therefore, OGG1 excises 8-oxoG mis-paired with adenine during DNA replication (3). MUTYH excises the adenine inserted opposite 8-oxoG in the template strand (4). OGG1 localizes to the nucleus and mitochondria, and is the predominant enzyme responsible for base excision repair (BER) of 8-oxoG lesions (8). The promoter of the $O G G 1$ gene contains a binding site for nuclear factor erythroid 2-related factor 2 (Nrf2), a transcription factor that upregulates the expression of a variety of antioxidant enzymes (9).

Plasma, which is known as the fourth fundamental state of matter, refers to a partially ionized gas in physics (10). Plasma produces ions and electrons, in addition to uncharged neutral atoms, free radicals and electrically excited atoms, which exhibit a high chemical reactivity and emit UV radiation (11). Previous reports have demonstrated that non-thermal plasma may be used to promote cell proliferation and wound healing, and to treat cancer (12-15). It is hypothesized that these properties of plasma are partially due to the formation of reactive oxygen species (ROS) (15-18).

Our recent study demonstrated that non-thermal dielectric barrier discharge (DBD) plasma generates ROS and promotes various types of damage to cellular components, including 
lipid membrane peroxidation, DNA breaks and protein carboxylation (19). These findings suggested that DBD plasma exerts cytotoxic effects via oxidative stress-induced damage to these components. The present study examined whether oxidative stress induced by DBD plasma exposure might affect the formation of 8-oxoG in HaCaT human keratinocytes.

\section{Materials and methods}

Reagents. N-acetyl cysteine (NAC), avidin-tetramethylrhodamine isothiocyanate (avidin-TRITC) and actin antibody (A2066; 1:2,000; a rabbit polyclonal antibody) were purchased from Sigma-Aldrich (Merck KGaA, Darmstadt, Germany). OGG1/2 (H-300) antibody (sc-33181; 1:1,000; a rabbit polyclonal antibody), Nrf2 (C-20) antibody (sc-722; 1:1,000; a rabbit polyclonal antibody) and mouse anti-rabbit IgG-FITC conjugated secondary antibody (sc-2359; 1:100) were purchased from Santa Cruz Biotechnology, Inc. (Dallas, TX, USA). The phospho-Nrf2 antibody (Ser40; 2073-1; 1:1,000; a rabbit monoclonal antibody) was purchased from Epitomics (Burlingame, CA, USA). The TATA box binding protein (TBP) antibody (ab818; 1:2,000; a mouse monoclonal antibody) was purchased from Abcam Inc. (Cambridge, MA, USA). The phospho-Akt (Ser473; 9271; 1:1,000; a rabbit polyclonal antibody) and Akt (9272; 1:1,000; a rabbit polyclonal antibody) antibodies were purchased from Cell Signaling Technology (Danvers, MA, USA). The goat anti-rabbit IgG-horseradish peroxidase conjugated secondary antibody (G21234; 1:10,000) and goat anti-mouse IgG-horseradish peroxidase conjugated secondary antibody (G21040; 1:10,000) were purchased from Invitrogen (Thermo Fisher Scientific, Inc., Waltham, MA, USA). All other chemicals and reagents were of analytical grade.

Cell culture and plasma exposure. The HaCaT human keratinocytes were obtained from Amore Pacific Corporation (Yongin, Korea) and maintained at $37^{\circ} \mathrm{C}$ in an incubator with $5 \% \mathrm{CO}_{2}$. Cells were grown in Dulbecco's modified Eagle's medium (Thermo Fisher Scientific Inc., Waltham, MA, USA) containing $10 \%$ heat-inactivated fetal calf serum (Thermo Fisher Scientific Inc.), $100 \mu \mathrm{g} / \mathrm{ml}$ streptomycin and $100 \mathrm{U} / \mathrm{ml}$ penicillin. Non-thermal DBD plasma was applied as described previously (19). The cell suspension was adjusted to a concentration of $2 \times 10^{5}$ cells $/ \mathrm{ml}$ and $11 \mathrm{ml}$ was placed into $60 \mathrm{~mm}$ dishes. Cells were exposed to DBD plasma for 1 , 2 and $3 \mathrm{~min}$. Positive controls were treated with $1 \mathrm{mM}$ NAC 30 min prior to DBD plasma exposure. Following plasma exposure, cells were incubated for $24 \mathrm{~h}$ prior to subsequent experiments.

Analysis of 8-oxoG level. Cellular DNA was isolated and purified using the genomic DNA purification kit (Promega Corporation, Madison, WI, USA) and quantified using a spectrophotometer. The quantity of 8-hydroxy-2'-deoxyguanosine $(8-\mathrm{OHdG})$, a nucleoside of 8 -oxoG, in the DNA was determined using the Bioxytech 8-OHdG ELISA kit (Oxis International, Tampa, FL, USA), according to the manufacturer's protocol. The quantity of $8-\mathrm{OHdG}$ was considered proportional to 8-oxoG. In addition, the quantity of 8-oxoG was determined via a fluorescent binding assay using avidin, which binds to 8-oxoG with high affinity (20). The cells were fixed and permeabilized with ice-cold methanol for $15 \mathrm{~min}$, and subsequently incubated with avidin-TRITC for $1 \mathrm{~h}$ at room temperature. 8-oxoG was visualized using a confocal microscope and LSM 5 PASCAL laser scanning software version 3.5 (Zeiss GmbH, Jena, Germany).

Reverse transcription-polymerase chain reaction ( $R T-P C R)$. Total RNA was isolated from cells using the total RNA extraction kit (Intron Biotechnology, Seongnam, Korea) and cDNA was amplified using reverse transcription reagent kit according to the manufacturer's protocol (25021; Intron Biotechnology). PCR amplifications of $O G G 1$ and GAPDH (a housekeeping gene) were performed as follows: An initial pre-denaturation step at $94^{\circ} \mathrm{C}$ for $2 \mathrm{~min}, 35$ cycles of denaturation at $94^{\circ} \mathrm{C}$ for $20 \mathrm{sec}$, annealing at $58^{\circ} \mathrm{C}$ for $30 \mathrm{sec}$ and extension at $72^{\circ} \mathrm{C}$ for $1 \mathrm{~min}$, and a final extension step at $72^{\circ} \mathrm{C}$ for $5 \mathrm{~min}$. Primer pairs (Bioneer Corporation, Daejeon, Korea) were as follows: Sense, 5'-CTGCCTTCTGGACAATCTTT-3' and antisense, 5'-TAGCCCGCCCTGTTCTTC-3' for human $O G G 1$; and sense, 5'-TCAAGTGGGGCGATGCTGGC-3' and antisense, 5'-TGCCAGCCCCAGCGTCAAAG-3' for human GAPDH. Amplified products were resolved by electrophoresis and photographed under UV light.

Transient transfection and OGG1 promoter luciferase assay. Cells were cultured at a density of $1 \times 10^{6}$ cells per $60 \mathrm{~mm}$ dish to maintain approximately $60-80 \%$ confluence. Cells were transiently transfected with a plasmid harboring the $O G G 1$ promoter using the transfection reagent Lipofectamine (Invitrogen; Thermo Fisher Scientific Inc.), according to the manufacturer's protocol. The $O G G 1$ promoter-luciferase construct was a generous gift from Professor Ho Jin You (Chosun University, Gwangju, Korea). Transfected cells were exposed to DBD plasma for $2 \mathrm{~min}$, with or without pretreatment with $1 \mathrm{mM}$ NAC for $30 \mathrm{~min}$. Cells were incubated for $24 \mathrm{~h}$ prior to analysis. Subsequently, cells were lysed with reporter lysis buffer (Promega Corporation), and the lysate was mixed with the luciferase assay reagent (Promega Corporation). The mixture was detected by a luminometer.

Protein extraction and western blot analysis. Cells were seeded in 100-mm culture plates at a density of $2 \times 10^{5}$ cells $/ \mathrm{ml}$. To extract total protein, cells were lysed on ice for $30 \mathrm{~min}$ using $150 \mu \mathrm{l}$ lysis reagent (Intron Biotechnology), and centrifuged at $13,000 \times \mathrm{g}$ at $4^{\circ} \mathrm{C}$ for $30 \mathrm{~min}$. To extract nuclear proteins, cells were lysed using the subcellular protein fractionation kit (Thermo Fisher Scientific Inc.). Protein concentrations of the cellular and nuclear extracts were determined using the Bradford assay. Aliquots of the lysates (20 $\mu \mathrm{g}$ protein) were boiled for $5 \mathrm{~min}$, electrophoresed on $10 \%$ SDS-polyacrylamide gels, and transferred onto nitrocellulose membranes (Bio-Rad Laboratories, Hercules, CA, USA). Membranes were incubated with the appropriate primary antibody for $2 \mathrm{~h}$ at room temperature, followed by a horseradish peroxidase-conjugated IgG secondary antibody for $1 \mathrm{~h}$ at room temperature. Protein bands were visualized by developing the blots with an enhanced chemiluminescence detection kit (GE Healthcare Life Sciences, Chalfont, UK) and exposing the membranes to autoradiography film (Thermo Fisher Scientific Inc.). 
Immunocytochemistry. Cells were plated onto coverslips, fixed with $1 \%$ paraformaldehyde for $30 \mathrm{~min}$ and permeabilized with $2 \%$ triton X-100 in PBS for 30 min (21). Subsequently, cells were blocked with $1 \%$ bovine serum albumin in PBS for $1 \mathrm{~h}$, incubated with OGG1 or Nrf2 primary antibodies for $2 \mathrm{~h}$ at room temperature and probed with a FITC-conjugated secondary antibody at 1:200 for $1 \mathrm{~h}$ at $37^{\circ} \mathrm{C}$. Following washing with PBS, cells were transferred onto microscope slides in mounting medium containing DAPI (Vector Laboratories, Burlingame, CA, USA). Slides were examined using a confocal microscope and images were captured using LSM 5 PASCAL laser scanning software version 3.5 (Zeiss $\mathrm{GmbH}$ ).

Statistical analysis. Statistical significance was determined using analysis of variance and Tukey's tests with version 3.5 of SigmaStat software (Systat Software Inc., San Jose, CA, USA). All values are presented as the mean \pm standard error. $\mathrm{P}<0.05$ was considered to indicate a statistically significant difference.

\section{Results}

Exposure to non-thermal DBD plasma increases 8-oxoG levels in HaCaT cells. Our previous study demonstrated that exposure of $\mathrm{HaCaT}$ cells to non-thermal DBD plasma for $2 \mathrm{~min}$ at $9.8 \mathrm{~J} / \mathrm{ml}$ reduced cell viability by $50 \%$ (19). Therefore, the same plasma dose was utilized in the present study. The quantity of 8-OHdG in DBD plasma-exposed HaCaT cells was investigated using an ELISA kit, and was considered to be proportional to the quantity of 8-oxoG. The 8-OHdG level in $\mathrm{HaCaT}$ cells exposed to DBD plasma were $1,571 \mathrm{ng} / \mathrm{mg}$, which was significantly greater compared with control cells (442 ng/mg); however, this increase was significantly suppressed in cells that were pretreated with the antioxidant NAC prior to plasma exposure (Fig. 1A). In addition, 8-oxoG was analyzed by confocal microscopy using avidin-TRITC (20). The fluorescence intensity of avidin-TRITC bound to 8-oxoG was elevated in DBD plasma-exposed cells compared with control cells; however, pretreatment of DBD plasma-exposed cells with NAC markedly reduced this (Fig. 1B). These results indicated that exposure of $\mathrm{HaCaT}$ cells to DBD plasma generated the oxidized DNA base 8-oxoG.

Non-thermal DBD plasma attenuates expression of OGG1 in HaCaT cells. The glycosylase enzyme OGG1 is responsible for the excision of 8-oxoG (22). mRNA expression level of $O G G 1$ in $\mathrm{HaCaT}$ cells was reduced by $\mathrm{DBD}$ plasma exposure (Fig. 2A). In addition, the transcriptional activity of the $O G G 1$ promoter was reduced in DBD plasma-exposed cells; however, pretreatment of cells with NAC attenuated this significantly (Fig. 2B). Furthermore, OGG1 protein expression was reduced by exposure to DBD plasma in a time-dependent manner (Fig. 2C), and NAC pretreatment reversed this decrease (Fig. 2D). Subsequently, immunocytochemical analysis of the control, plasma-exposed and NAC-pretreated plasma-exposed cells was performed to determine the cellular distribution of the OGG1 protein. This revealed that OGG1 expression in HaCaT cells exposed to DBD plasma was reduced compared with control cells; this decrease was attenuated in NAC-pretreated cells (Fig. 2E). These results indicated that DBD plasma exposure reduces the expression of OGG1 at the mRNA and
A

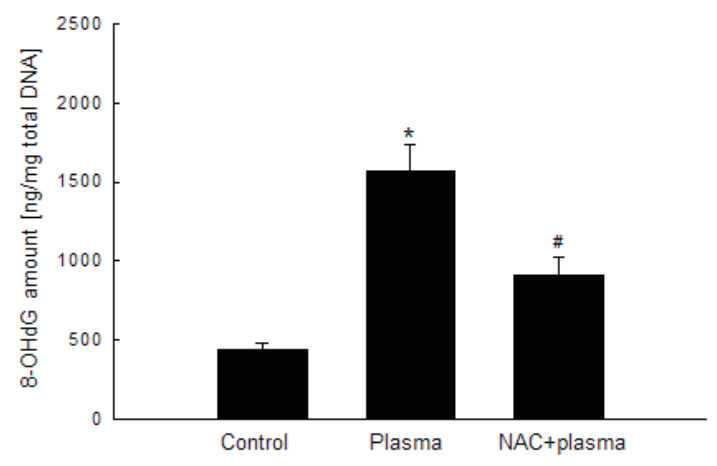

B

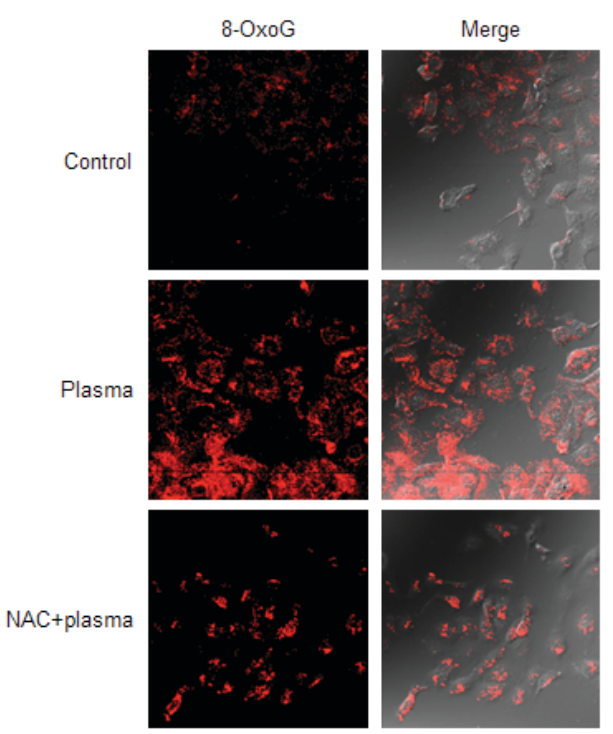

Figure 1. Exposure of HaCaT cells to non-thermal DBD plasma enhances the quantity of 8-oxoG. Cells were exposed to plasma for $2 \mathrm{~min}$, with or without pretreatment with the antioxidant NAC. (A) 8-OHdG level was determined using an ELISA kit. Data are expressed as the mean \pm standard error of triplicate samples within the same experiment. ${ }^{\text {}} \mathrm{P}<0.05$ vs. control cells; ${ }^{*} \mathrm{P}<0.05$ vs. plasma-exposed cells. (B) Visualization of 8-oxoG via avidin-TRITC staining in control cells, plasma-exposed cells, and pretreatment of NAC and plasma-exposed cells by confocal microscopy. 8-oxoG, 8-oxoguanine; NAC, N-acetyl cysteine; 8-OHdG, 8-hydroxy-2'-deoxyguanosine; TRITC, tetramethylrhodamine isothiocyanate.

protein level in HaCaT cells; however, pretreatment with NAC suppresses this effect.

Non-thermal DBD plasma attenuates nuclear translocation of Nrf2 in HaCaT cells. Nrf2, a transcription factor that regulates the expression levels of antioxidant and detoxifying enzymes (23), binds to antioxidant response elements in the $O G G 1$ promoter and regulates its expression $(9,24)$. Western blot analysis revealed that the expression levels of nuclear Nrf2 and phospho-Nrf2 in HaCaT cells were reduced by DBD plasma in a time-dependent manner (Fig. 3A); however, the expression levels of the two proteins were restored in cells that were pretreated with NAC prior to plasma exposure (Fig. 3B). To identify the effect of DBD plasma on the localization of the Nrf2 protein, immunocytochemical analysis was performed 
A

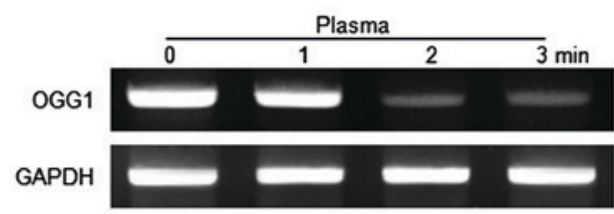

B

C

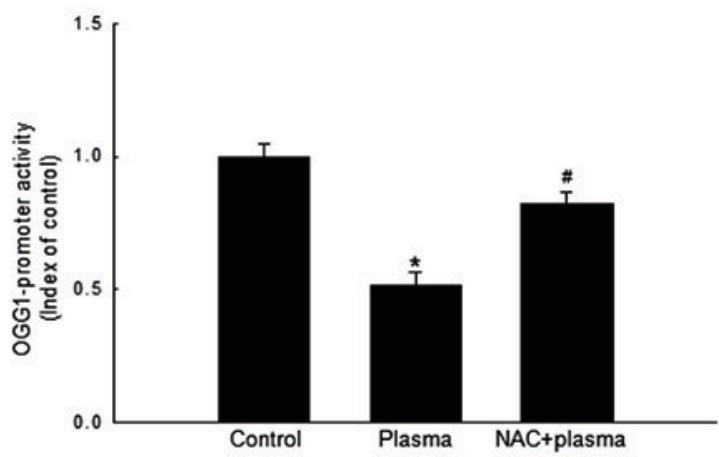

$\mathbf{E}$
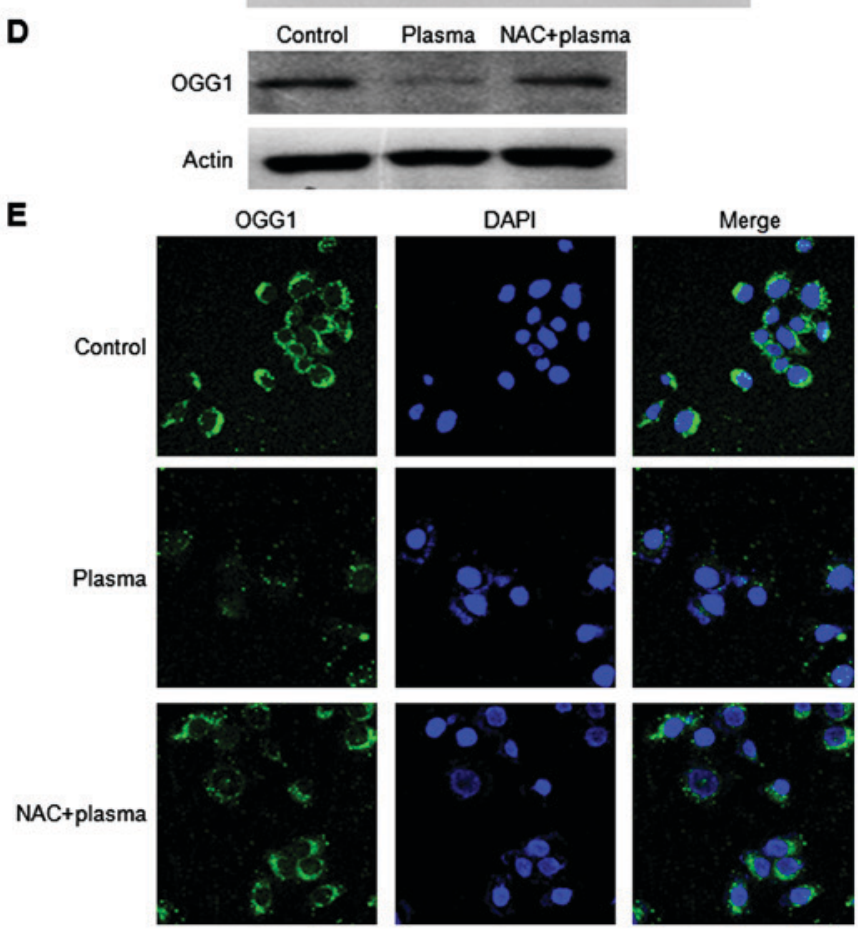

A

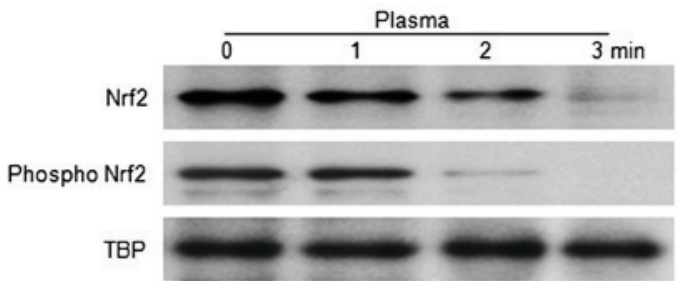

B

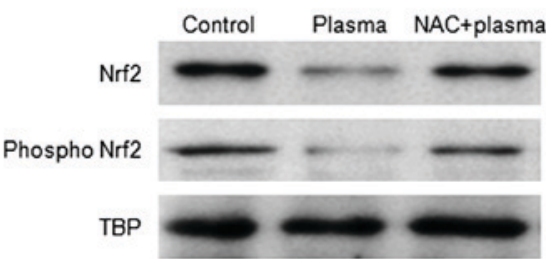

C
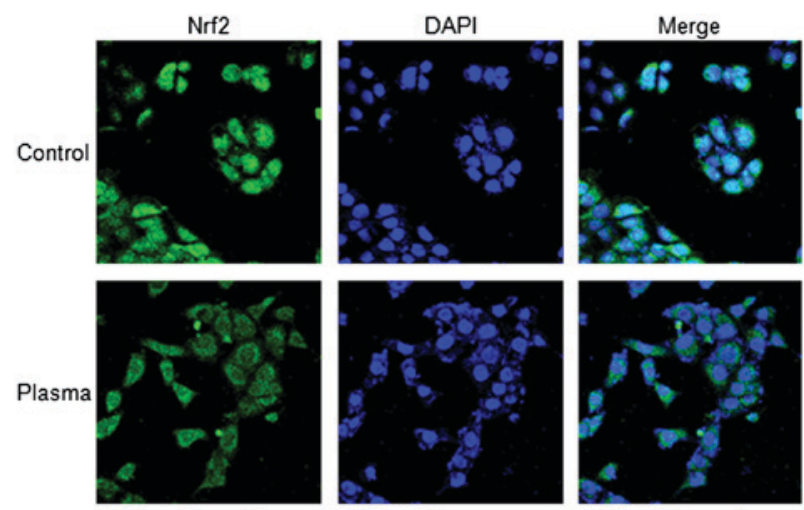

NAC+plasma
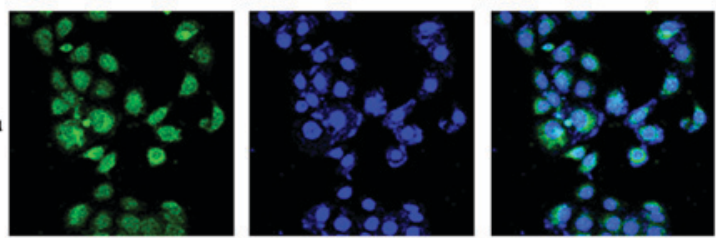

Figure 3. Exposure to non-thermal DBD plasma reduces the nuclear expression levels of Nrf2 and phospho-Nrf2 in HaCaT cells. (A) Western blot analysis of nuclear Nrf2 and phospho-Nrf2 in cells that were exposed to DBD plasma for 1, 2 or 3 min; TBP served as a loading control. (B) Western blot analysis of nuclear proteins in control cells, DBD plasma-exposed cells, and pretreatment of NAC and plasma-exposed cells. Cells were incubated for $24 \mathrm{~h}$ prior to analysis. (C) The localization of Nrf2 in control cells, DBD plasma-exposed cells, and pretreatment of NAC and plasma-exposed cells was assessed by immunocytochemistry. Green fluorescence indicates Nrf2 and blue fluorescence indicates nuclei. DBD, dielectric barrier discharge; Nrf2, nuclear factor erythroid 2-related factor 2; TBP, TATA box binding protein; NAC, N-acetyl cysteine.

(Fig. 3C). The nuclear localization of Nrf2 was reduced by exposure of $\mathrm{HaCaT}$ cells to DBD plasma, as demonstrated by a decrease in Nrf2 and DAPI co-staining. However, this effect was attenuated by pretreatment with NAC. These results indicated that nuclear expression of Nrf2 was reduced by exposure to DBD plasma, and that this reduction was partly abrogated by pretreatment with NAC.

Non-thermal DBD plasma attenuates phosphorylation of Akt in $\mathrm{HaCaT}$ cells. Nrf2 is sequestered in the cytoplasm by Kelch-like ECH-associated protein 1 (Keap1). However, Nrf2 may translocate to the nucleus following phosphorylation by activated Akt, which serves a role in a cell survival pathway (25). The expression level of the active phospho-Akt 
A

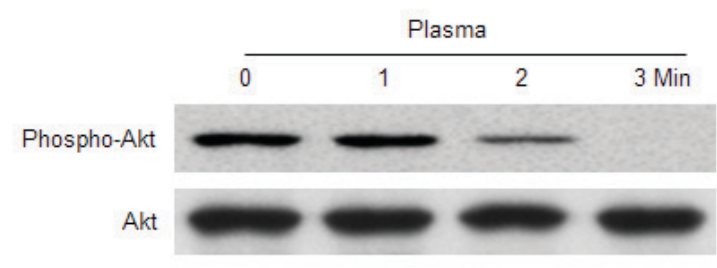

B

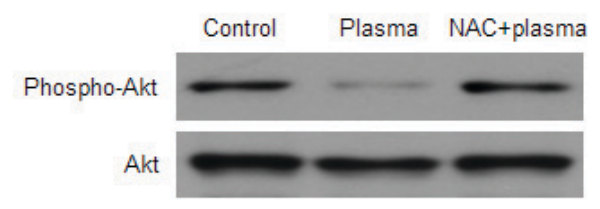

Figure 4. Exposure to non-thermal DBD plasma reduces the level of activated Akt in $\mathrm{HaCaT}$ cells. (A) Western blot analysis of Akt and phospho-Akt protein expression levels in cells treated with DBD plasma for 1, 2 or 3 min. (B) Western blot analysis of Akt and phospho-Akt protein expression levels in control cells, DBD plasma-exposed cells, and pretreatment of NAC and plasma-exposed cells. Cells were incubated for $12 \mathrm{~h}$ prior to analysis. DBD, dielectric barrier discharge; NAC, N-acetyl cysteine.

protein was reduced by exposure of $\mathrm{HaCaT}$ cells to DBD plasma in a time-dependent manner (Fig. 4A). Furthermore, the reduced phosphorylation of Akt was blocked by pretreatment of cells with NAC (Fig. 4B). These results suggested that exposure to DBD plasma reduces the phosphorylation of Akt, and that this modification may be restored by pretreatment with NAC.

\section{Discussion}

Exposure to non-thermal plasma generates ROS and induces oxidative stress in living cells and tissues (16-18). Our previous study revealed that exposure of $\mathrm{HaCaT}$ cells to non-thermal DBD plasma generated ROS and resulted in DNA damage (19). The present study focused on the mechanism underlying DNA damage induced by DBD plasma by investigating the generation of the modified DNA base, 8-oxoG, the most stable product of oxidative DNA damage caused by ROS. The 8 -oxoG base is considered highly mutagenic as it may pair with adenine as well as cytosine, and accumulates in nuclear and mitochondrial DNA (26). As guanine is more vulnerable to oxidation than other nitrogen bases, ROS may readily oxidize it to 8-oxoG. However, OGG1 identifies 8-oxoG bases in DNA and initiates BER to remove them (27). The DNA glycosylase activity of OGG1 preferentially excises 8 -oxoG bases that are paired with cytosine. A DNA glycosylase encoded by the MUTYH gene, a homolog of Escherichia coli mutY, excises adenines located opposite 8-oxoG in the template strand (28). Once cytosine is inserted and adenine is removed, 8-oxoG can be removed by OGG1 via the BER mechanism (29).

In the present study, exposure of $\mathrm{HaCaT}$ cells to DBD plasma enhanced the level of 8-oxoG and reduced level of OGG1. By contrast, pretreatment of cells with NAC, an established ROS scavenger, suppressed these effects. The $O G G 1$ gene is regulated by binding of the Nrf2 transcription factor to antioxidant response elements in its promoter region $(9,27)$. The transcriptional activity of $\mathrm{Nrf} 2$ requires its translocation to the nucleus, which is regulated by Keap1-mediated anchoring in the cytoplasm (30). The Nrf2-Keap1 complex dissociates to block the ubiquitination of Nrf2, and translocation of this transcription factor is initiated by its phosphorylation at serine 40 and specific threonine residues, in addition to modification of cysteine residues in Keap1 $(31,32)$. Phosphorylation of Nrf2 is achieved by various kinases including Akt (33). In the present study, the expression levels of Nrf2 and phsopho-Nrf2 in the nuclear fraction by DBD plasma exposure was reduced (Fig. 3A). This might be due to the downregulation of transcription of Nrf2 and Akt pathway (upstream to phosphorylate Nrf2) by DBD plasma exposure.

In conclusion, the results of the present study revealed that DBD plasma exposure generates 8-oxoG and disrupts OGG1 gene transcription by downregulation of the Akt-Nrf2 signaling pathway. However, pretreatment with NAC, a well-known scavenger of various free radicals, including ROS, suppressed 8-oxoG level and activated the Akt-Nrf2-OGG1 signaling pathway.

\section{Acknowledgements}

The present study was supported by the R\&D Program of Plasma Advanced Technology for Agriculture and Food (Plasma Farming) via the National Fusion Research Institute of Korea (NFRI), funded by the Government.

\section{References}

1. Fortini P, Pascucci B, Parlanti E, D'Errico M, Simonelli V and Dogliotti E: 8-Oxoguanine DNA damage: At the crossroad of alternative repair pathways. Mutat Res 531: 127-139, 2003.

2. Bruner SD, Norman DP and Verdine GL: Structural basis for recognition and repair of the endogenous mutagen 8-oxoguanine in DNA. Nature 403: 859-866, 2000.

3. Nakabeppu Y: Cellular levels of 8-oxoguanine in either DNA or the nucleotide pool play pivotal roles in carcinogenesis and survival of cancer cells. Int J Mol Sci 15: 12543-12557, 2014.

4. Görgens H, Müller A, Krüger S, Kuhlisch E, König IR, Ziegler A, Schackert HK and Eckelt U: Analysis of the base excision repair genes MTH1, OGG1 and MUTYH in patients with squamous oral carcinomas. Oral Oncol 43: 791-795, 2007.

5. Klungland A, Rosewell I, Hollenbach S, Larsen E, Daly G, Epe B, Seeberg E, Lindahl T and Barnes DE: Accumulation of premutagenic DNA lesions in mice defective in removal of oxidative base damage. Proc Natl Acad Sci USA 96: 13300-13305, 1999.

6. Boiteux S and Radicella JP: The human OGG1 gene: Structure, functions, and its implication in the process of carcinogenesis. Arch Biochem Biophys 377: 1-8, 2000.

7. De Souza-Pinto NC, Eide L, Hogue BA, Thybo T, Stevnsner T, Seeberg E, Klungland A and Bohr VA: Repair of 8-oxodeoxyguanosine lesions in mitochondrial dna depends on the oxoguanine dna glycosylase (OGG1) gene and 8-oxoguanine accumulates in the mitochondrial dna of OGG1-defective mice. Cancer Res 61: 5378-5381, 2001.

8. Sampath H, McCullough AK and Lloyd RS: Regulation of DNA glycosylases and their role in limiting disease. Free Radic Res 46: 460-478, 2012.

9. Singh B, Chatterjee A, Ronghe AM, Bhat NK and Bhat HK: Antioxidant-mediated up-regulation of OGG1 via NRF2 induction is associated with inhibition of oxidative DNA damage in estrogen-induced breast cancer. BMC Cancer 13: 253, 2013.

10. Luo QZ, D'Angelo N and Merlino RL: Shock formation in a negative ion plasma. Phys Plasmas 5: 2868, 1998.

11. Goree J: Charging of particles in a plasma. Plasma Sources Sci Technol 3: 400, 1994.

12. Leduc M, Guay D, Leask RL and Coulombe S: Cell permeabilization using a non-thermal plasma. New J Phys 11: 115021, 2009. 
13. Kalghatgi S, Friedman G, Fridman A and Clyne AM: Endothelial cell proliferation is enhanced by low dose non-thermal plasma through fibroblast growth factor-2 release. Ann Biomed Eng 38: 748-757, 2010.

14. Ermolaeva SA, Varfolomeev AF, Chernukha MY, Yurov DS, Vasiliev MM, Kaminskaya AA, Moisenovich MM, Romanova JM, Murashev AN, Selezneva II, et al: Bactericidal effects of non-thermal argon plasma in vitro, in biofilms and in the animal model of infected wounds. J Med Microbiol 60: 75-83, 2011.

15. Vandamme M, Robert E, Lerondel S, Sarron V, Ries D, Dozias S, Sobilo J, Gosset D, Kieda C, Legrain B, et al: ROS implication in a new antitumor strategy based on non-thermal plasma. Int $\mathbf{J}$ Cancer 130: 2185-2194, 2012.

16. Ahn HJ, Kim KI, Kim G, Moon E, Yang SS and Lee JS: Atmospheric-pressure plasma jet induces apoptosis involving mitochondria via generation of free radicals. PLoS One 6: e28154, 2011.

17. Arjunan KP and Clyne AM: Non-thermal dielectric barrier discharge plasma induces angiogenesis through reactive oxygen species. Conf Proc IEEE Eng Med Biol Soc 2011: 2447-2450, 2011.

18. Ishaq M, Kumar S, Varinli H, Han ZJ, Rider AE, Evans MD, Murphy AB and Ostrikov K: Atmospheric gas plasma-induced ROS production activates TNF-ASK1 pathway for the induction of melanoma cancer cell apoptosis. Mol Biol Cell 25: 1523-1531, 2014.

19. Kim KC, Piao MJ, Madduma Hewage SR, Han X, Kang KA, Jo JO, Mok YS, Shin JH, Park Y, Yoo SJ and Hyun JW: Non-thermal dielectric-barrier discharge plasma damages human keratinocytes by inducing oxidative stress. Int J Mol Med 37: 29-38, 2016.

20. Struthers L, Patel R, Clark J and Thomas S: Direct detection of 8-oxodeoxyguanosine and 8-oxoguanine by avidin and its analogues. Anal Biochem 255: 20-31, 1998

21. Heo HJ, Kim HK, Youm JB, Cho SW, Song IS, Lee SY, Ko TH, Kim N, Ko KS, Rhee BD and Han J: Mitochondrial pyruvate dehydrogenase phosphatase 1 regulates the early differentiation of cardiomyocytes from mouse embryonic stem cells. Exp Mol Med 48: e254, 2016.

22. Hazra TK, Izumi T, Boldogh I, Imhoff B, Kow YW, Jaruga P, Dizdaroglu $M$ and Mitra S: Identification and characterization of a human DNA glycosylase for repair of modified bases in oxidatively damaged DNA. Proc Natl Acad Sci USA 99: 3523-3528, 2002 .
23. Kang KA and Hyun JW: Oxidative stress, Nrf2 and epigenetic modification contribute to anticancer drug resistance. Toxicol Res 33: 1-5, 2017.

24. Piao MJ, Kim KC, Choi JY, Choi J and Hyun JW: Silver nanoparticles down-regulate Nrf2-mediated 8-oxoguanine DNA glycosylase 1 through inactivation of extracellular regulated kinase and protein kinase B in human chang liver cells. Toxicol Lett 207: 143-148, 2011

25. Wang L, Chen Y, Sternberg P and Cai J: Essential roles of the PI3 kinase/Akt pathway in regulating Nrf2-dependent antioxidant functions in the RPE. Invest Ophthalmol Vis Sci 49: 1671-1678, 2008.

26. Nakabeppu Y, Sakumi K, Sakamoto K, Tsuchimoto D, Tsuzuki T and Nakatsu Y: Mutagenesis and carcinogenesis caused by the oxidation of nucleic acids. Biol Chem 387: 373-379, 2006.

27. Radicella JP, Dherin C, Desmaze C, Fox MS and Boiteux S: Cloning and characterization of hOGG1, a human homolog of the OGG1 gene of Saccharomyces cerevisiae. Proc Natl Acad Sci USA 94: 8010-8015, 1997.

28. Slupska MM, Luther WM, Chiang JH, Yang H and Miller JH: Functional expression of hMYH, a human homolog of the Escherichia coli MutY protein. J Bacteriol 181: 6210-6213, 1999.

29. Ohtsubo T, Nishioka K, Imaiso Y, Iwai S, Shimokawa H, Oda H, Fujiwara T and Nakabeppu Y: Identification of human MutY homolog (hMYH) as a repair enzyme for 2-hydroxyadenine in DNA and detection of multiple forms of hMYH located in nuclei and mitochondria. Nucleic Acids Res 28: 1355-1364, 2000.

30. Jung JS, Lee SY, Kim DH and Kim HS: Protopanaxatriol ginsenoside Rh1 upregulates phase II antioxidant enzyme gene expression in rat primary astrocytes: Involvement of MAP kinases and Nrf2/are signaling. Biomol Ther (Seoul) 24: 33-39, 2016.

31. Kensler TW, Wakabayashi N and Biswal S: Cell survival responses to environmental stresses via the Keap1-Nrf2-are pathway. Annu Rev Pharmacol Toxicol 47: 89-116, 2007.

32. Sykiotis GP and Bohmann D: Stress-activated cap'n'collar transcription factors in aging and human disease. Sci Signal 3: re3, 2010.

33. Boutten A, Goven D, Artaud-Macari E, Boczkowski J and Bonay M: NRF2 targeting: A promising therapeutic strategy in chronic obstructive pulmonary disease. Trends Mol Med 17: 363-371, 2011. 